\title{
Phagocytosis of neutrophil polymorphonuclears by macrophages in human bone marrow: importance in granulopoiesis
}

\author{
C DRESCH,* G FLANDRIN,* AND J BRETON-GORIUS $\dagger$
}

From the *Institut de Recherche sur les Maladies du Sang, Hôpital Saint-Louis, Université Paris VII, FRA $n^{\circ} 4$ INSERM, and the †Unité INSERM de Recherches sur les Anémies, Hôpital Henri Mondor, Créteil, Paris, France

SUMMARY The cytological and electron-microscopic appearance of neutrophil phagocytosis by macrophages in normal human bone marrow is described. This feature can be observed in every normal bone marrow and is especially frequent in autoimmune disease. Bone marrow phagocytosis of polymorphonuclear neutrophils seems to be a physiological process resulting from the random egress of neutrophils from bone marrow to blood.

Erythrophagocytosis by macrophages in human bone marrow has been known for a long time and is well described. Quantitatively, its effect on erythropoïesis is not important, due to the long intravascular lifetime of red cells compared to the intramedullary sojourn of reticulocytes. To our knowledge, phagocytosis of neutrophil polymorphonuclears has been studied only in vitro and with guinea-pig cells by Brewer, ${ }^{1}$ and its significance has not been evaluated. Several recent reports have questioned the notion of a pipe-line maturation and release of neutrophils from bone marrow to blood, that is, a strict agedependent process, which is the orthodox model of granulopoiesis. ${ }^{23}$ The presence of band cells in normal blood (3\% to $15 \%$ of neutrophils according to the criteria used) and the simultaneous emergence of labelled band cells and polymorphonuclears in blood after ${ }^{3} \mathrm{H}$-thymidine injection ${ }^{4}{ }^{5}$ are arguments against this 'first in, first out' neutrophil maturation principle. Meuret ${ }^{6}$ proposed a model in which the emigration potential of neutrophils gradually develops with maturation. Walle ${ }^{7}$ proposed a model in which one subpopulation of granulocytes leaves the bone marrow at random and another subpopulation goes through the storage and maturation pool. All these models depend upon the absence of intramedullary mortality of polymorphonuclears in bone marrow and are consistent with a half-time of disappearance from blood of 6-8 hours, that is, a blood granulocyte turnover rate of $50-60 \times 10^{6} \mathrm{~kg}^{-1} \mathrm{~h}^{-1} .^{3}$

Received for publication 21 January 1980
We have shown ${ }^{8}$ that the half-time of disappearance of granulocytes in blood is $18 \pm 2 \cdot 2 \mathrm{~h}$, that is, the granulocyte turnover rate is $27 \pm 5 \times 10^{6} \mathrm{~kg}^{-1} \mathrm{~h}^{-1}$. These data were recently confirmed by Steinbach et al., ${ }^{9}$ who used continuous ${ }^{3} \mathrm{H}$-thymidine labelling and found a half-life of neutrophils of $17 \cdot 3 \pm 1 \cdot 4 \mathrm{~h}$. Since most authors agree, with small variations, on the value of the cell influx in the non-proliferating pool of granulopoiesis, a halving of the granulocyte turnover rate implies intramedullary death in this non-proliferative pool. We attempted to determine if phagocytosis of polymorphonuclears was a general or exceptional phenomenon and could be the cytological expression of this 'ineffective' granulopoiesis.

\section{Methods}

Normal bone marrow taken by iliac or sternal puncture was stained with May-Grünwald Giemsa stain for cytological studies. A cytochemical peroxidase reaction was performed in some cases. For ultrastructural studies, the cytochemical reaction with diaminobenzidine for myeloperoxidase activity was used $^{10}$ after prefixation by glutaraldehyde according to our standard technique. ${ }^{11}$

\section{Results}

Figures 1 to 3 show normal macrophages with polymorphonuclear neutrophils in their cytoplasm in various stages of pyknosis. In Fig. 1, a polymorphonuclear is nearly intact within a vacuole; 


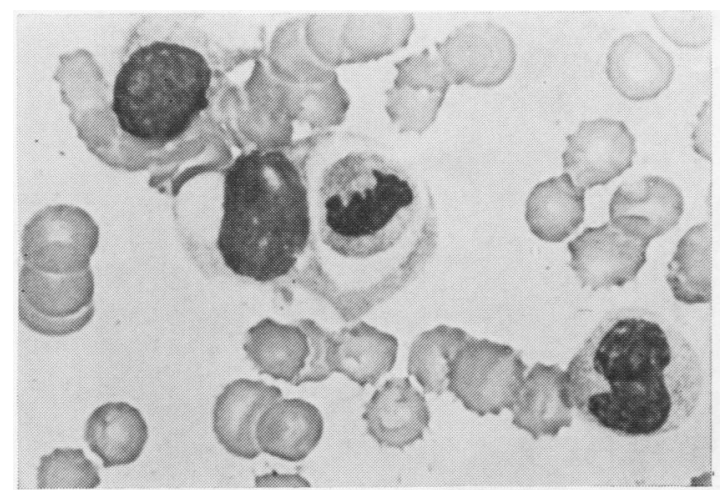

1

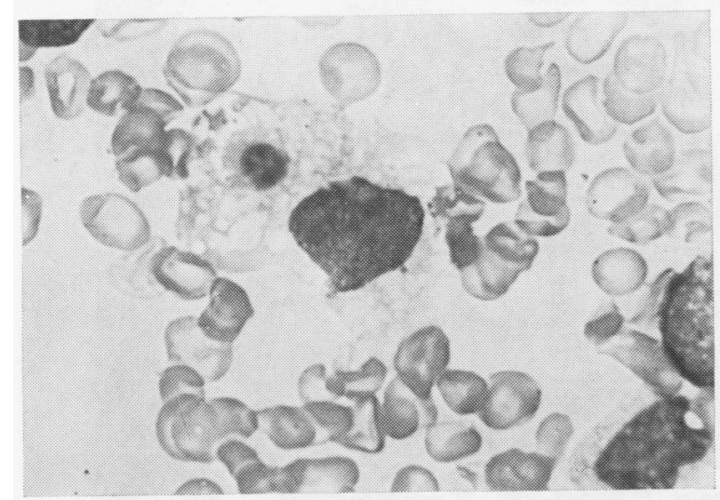

2

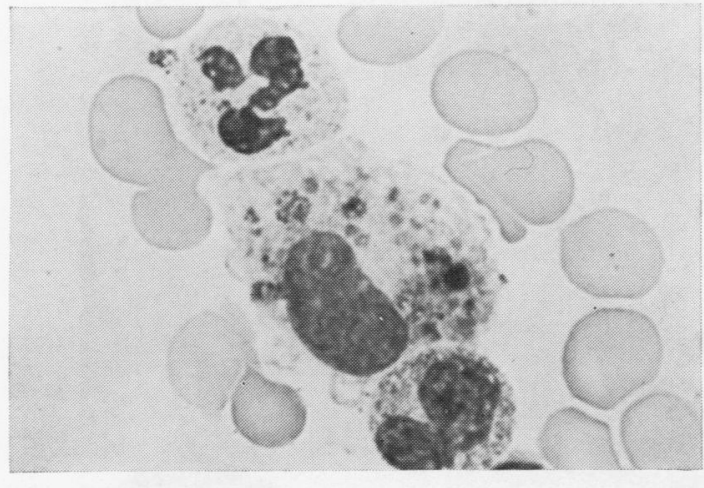

Figs 1, 2, and 3 Normal bone marrow cytology. MayGrünwald Giemsa staining, $\times 800$.

in Fig. 2, a shrunken, mummified polymorphonuclear is still recognisable by the shape of its nucleus; and in Fig. 3, only fragments of nuclear pyknosis remain. This appearance is not necessarily indicative of neutrophil ingestion. At the stage of Fig. 2, the appearance still seems quite specific for polymorphonuclear ingestion, as could be confirmed by the peroxidase cytochemical reaction. It was found in all normal bone marrow examined, and was more frequent in inflammatory and autoimmune disease, although the phenomenon could not be quantitated. Figure 4 shows a phagosome in a macrophage containing the remains of a polymorphonuclear neutrophil. The pyknotic nucleus (corresponding to Fig. 2 in cytology) is easily recognisable. The dense material, indicating the positivity of the diaminobenzidine reactions, indicates myeloperoxidase activity.

\section{Discussion}

Phagocytosis of polymorphonuclear neutrophils by macrophages was observed in normal bone marrow when sought and seems to be a physiological phenomenon. The appearance of the two last stages of phagocytosis seen in cytological studies corresponds to the two ultrastructural stages described by Brewer ${ }^{1}$ after incubation in vitro. It is noteworthy that these incubations lasted for 15-20 minutes, showing that the phagocytosis and pyknosis process is very rapid. This explains why it is not often seen and cannot be quantitated.

An approximation of the importance of this phenomenon can be assessed from bone marrow and blood kinetics. The discrepancy between the cellular outflow of the proliferative pool of granulopoiesis $\left(59 \times 10^{6} \mathrm{~kg}^{-1} \mathrm{~h}^{-1}\right.$ according to the data of Dancey' or Donohue ${ }^{13}$ for the entire bone marrow cell pool, to $53 \times 10^{6} \mathrm{~kg}^{-1} \mathrm{~h}^{-1}$ according to Harrison ${ }^{14}$ ) and blood granulocyte turnover $\left(27 \times 10^{6} \mathrm{~kg}^{-1} \mathrm{~h}^{-1}\right)^{8}$ would yield an estimated $50 \%$ death in the nonproliferative pool. A mathematical simulation of granulopoiesis with a random egress of polymorphonuclears from the bone marrow to blood after a minimum $20 \mathrm{~h}$ sojourn for band polymorphonuclears in bone marrow furnished $20 \%$ death in the polymorphonuclear pool (manuscript in preparation), corresponding with the 15 to $20 \%$ 'ineffective granulopoiesis' found in dogs by Deubelbeiss. ${ }^{15}$ Bone marrow to blood neutrophil release could, however, be more complex than a pure random process, either dependent on maturation, as suggested by Meuret, ${ }^{6}$ or both random and age-dependent, as suggested by Walle.? Whatever the mechanism, the constancy of neutrophil phagocytosis implies mortality in the storage or maturation pool, that is, an 'ineffective' granulopoiesis. Ineffective granulopoiesis has been suggested by Boll ${ }^{16}$ in human granulopoiesis, but only in the proliferative pool. We did not find any evidence of cell death at the promyelocyte stage, but cell death at the poly- 


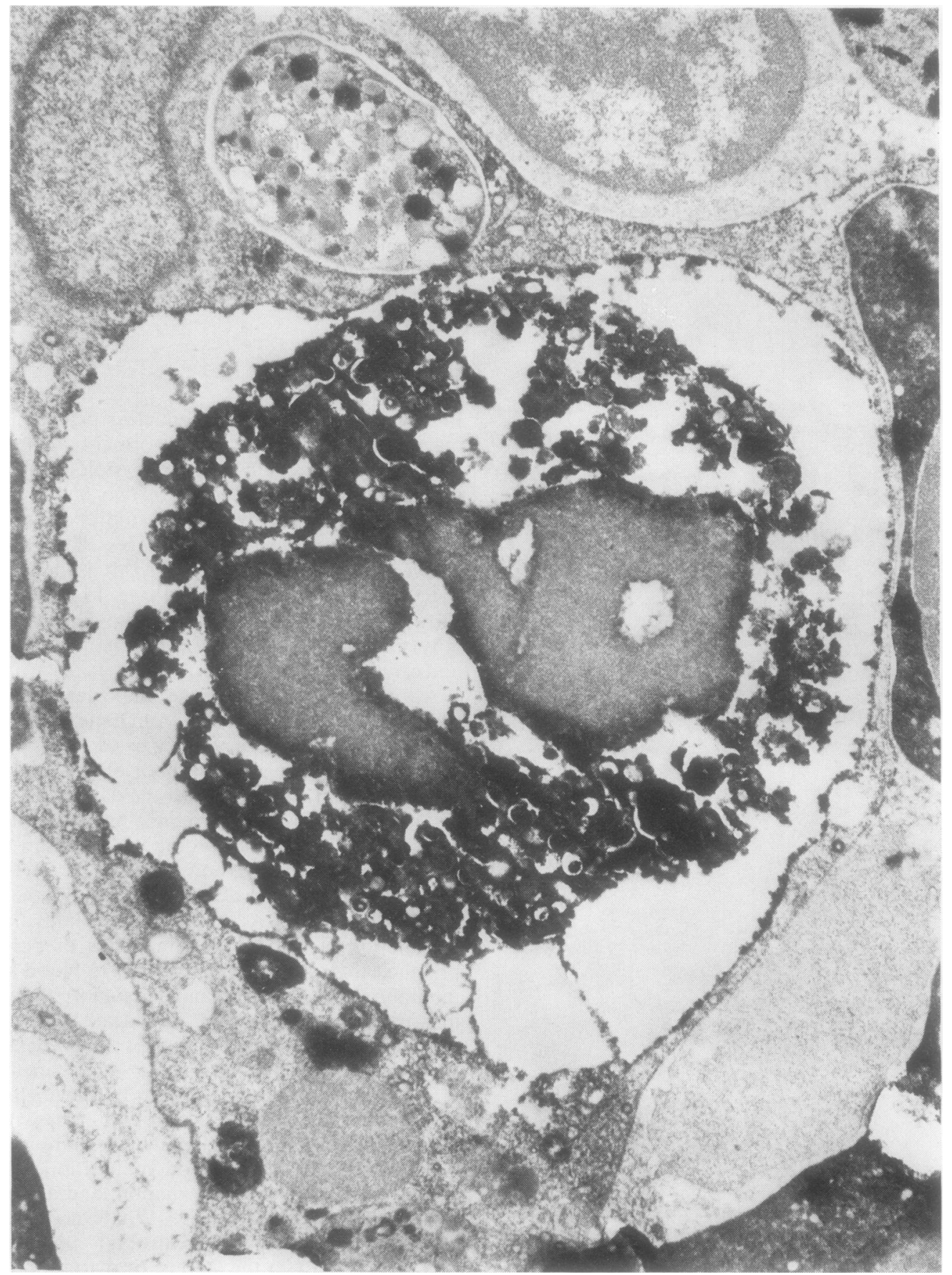

Fig. 4 Electron-microscopic appearance of polymorphonuclear leucocyte phagocytosed hy a macrophage. Diaminobenzidine reaction - osmium tetroxide $\times 12000$. 
morphonuclear stage would be the normal consequence of random egress. Kimball ${ }^{17}$ found, with etiocholanolone mobilisation, normal or increased granulocyte bone marrow reserve in rheumatoid arthritis, Sjögren's disease, and lupus erythematosus. We also found much leucocyte phagocytosis in cases of Sjögren's disease. Neutrophil phagocytosis thus appears to be a physiological process, a consequence of the random egress of polymorphonuclears from the bone marrow to blood, constituting a shortterm means of increasing granulocyte production. Neutrophil phagocytosis would decrease when the egress rate into blood is enhanced (or production increased), as shown by an increase in circulating band cells in bacterial infections ${ }^{\mathbf{1 8}}$ or after etiocholanolone injection. ${ }^{19}$ Neutrophil phagocytosis would be increased when maturation time is long, as in autoimmune disease, in certain bone marrow intoxications, or in carcinomas ${ }^{17-20}$ where neutropenia seems to result primarily from maturation abnormalities.

\section{References}

${ }^{1}$ Brewer DB. Electron-microscope observations on the phagocytosis of neutrophil polymorphonuclear leucocytes by macrophages. J Path Bact 1964;88:307-9.

${ }^{2}$ Cronkite EP, Vincent PC. Granulopoiesis. In: Hemopoietic Cellular Proliferation. F Stohlman, ed. New York: Grune and Stratton, 1970;211-8.

${ }^{3}$ Cartwright GE, Athens JW, Wintrobe MM. The kinetics of granulocytopoiesis in normal man. Blood 1964;24:780803.

4 Fliedner TM, Cronkite EP, Killmann SA, Bond VP. Granulocytopoiesis. II. Emergence and pattern of labeling of neutrophilic granulocytes in humans. Blood 1964;24:683-95.

${ }^{5}$ Clarkson B, Ohkita T, Ota K, Fried J. Studies of cellular proliferation in human leukemia. I. Estimation of growth rates of leukemic and normal hematopoietic cells in two adults with acute leukemia given single injections of tritiated thymidine. J Clin Invest 1967;46:506-13.

- Meuret G, Bammert J, Gessner U. Neutrophil marrow release, a system analysis. Blut $1976 ; 33: 389-402$.
${ }^{7}$ Walle AJ, Parwaresch MR. Normal human eosinophil kinetics. International Society of Haematology. European and African Division fifth Meeting. 1979; Abstracts IV, 49.

${ }^{8}$ Dresch $\mathrm{C}$, Najean Y, Bauchet J. Kinetic studies of ${ }^{51} \mathrm{Cr}$ and $\mathrm{DF}^{32} \mathrm{P}$ labelled granulocytes. Brit J Haemat 1975;29:6780.

${ }^{9}$ Steinbach KH, Schick, P, Trepel F, et al. Estimation of kinetic parameters of neutrophilic, eosinophilic and basophilic granulocytes in human blood. Blut 1979:39: 27-38.

${ }^{10}$ Graham RC, Karnovsky MJ. The early stages of absorption of injected horseradish peroxidase in the proximal tubules of mouse kidney. Ultrastructural cytochemistry by a new technique. J Histochem Cytochem 1966;14:291302.

11 Breton-Gorius J, Houssay D, Dreyfus B. Partial myeloperoxidase deficiency in a case of preleukemia. Brit $J$ Haema: 1975;30:273-8.

12 Dancey JT, Deubelbeiss KA, Harker LA, Finch CA. Neutrophil kinetics in man. J Clin Invest 1976;58:705-15.

${ }^{13}$ Donohue DM, Reiff RH, Hanson ML, Betson Y, Finch CA. Quantitative measurement of the erythrocytic and granulocytic cells of the marrow and blood. J Clin Invest 1958;37:1571-6.

${ }^{14}$ Harrison WJ. The total cellularity of the bone marrow in man. J Clin Pathol 1962;15:254-9.

${ }^{5}$ Deubelbeiss KA, Dancey JT, Harker LA, Finch CA. Neutrophil kinetics in the dog. J Clin Invest 1975;55:8339.

${ }^{16}$ Boll ITM, Fuchs G. A kinetic model of granulocytopoiesis. Exp Cell Res 1970;61:147-52.

${ }_{17}$ Kimball HR, Wolff SM, Talal N, Plotz PH, Decker JL. Marrow granulocyte reserves in rheumatic diseases. Arthritis Rheum 1973;16:345-52.

${ }_{18}$ Mathy KA, Koepke JA. The clinical usefulness of segmented stab neutrophil criteria for differential leukocyte counts. Am J Clin Path 1974;61 Suppl 6:947-58.

19 Mishler JM, Sharp AA. Adrenaline: Further discussion of its role in the mobilization of neutrophils. Scand $J$ Haemat 1976;17:78-80.

${ }^{20}$ Dresch C, Faille A, Bauchet J, Najean Y. Studies of granulocyte kinetics in normal and granulocytopenic subjects. Biomedicine 1975;22:145-57.

Requests for reprints to: Dr C Dresch, Institut de Recherche sur les Maladies du Sang, Hôpital SaintLouis, Université Paris VII, France. 